\title{
Effects of Some Selected Factors on Blood Glucose Level of the Diabetic Patients: Evidence from Rajshahi City of Bangladesh
}

\author{
B. Noor ${ }^{1}$, J. A. M. S. Rahman, and K. Hossain \\ Department of Population Science and Human Resource Development, University of Rajshahi, \\ Rajshahi-6205, Bangladesh
}

Received 29 May 2009, accepted in final revised form 17 November 2009

\begin{abstract}
This study presumes the existence of causal framework interlinking different predictor variables with the response variables. That is why it determines the risk and concerned factors, which affect blood sugar level of the diabetic patients either directly or indirectly or through making implied effect by the optional factors. Data have been collected from two diabetic diagnostic centers in Rajshahi City. The result implies that blood glucose level of both tablet and insulin users have positive and significant relation to systolic pressure, diastolic pressure and calorie intake. For both tablet and insulin users, body mass index (BMI) affects blood sugar most prominently through walking distance covered by the patients. The index, for instance, is found to be $69.74 \%$ and $58.82 \%$ for the tablet and insulin users, respectively. Thus controlling BMI through taking regulatory calorie intake, controlling blood pressure (both systolic and diastolic pressure) a patient could find himself or herself in the safe zone.
\end{abstract}

Keywords: Diabetic mellitus; Type-I and Type-II diabetic; Blood glucose level; Systolic pressure; Diastolic pressure.

(C) 2010 JSR Publications. ISSN: 2070-0237 (Print); 2070-0245 (Online). All rights reserved.

DOI: 10.3329/jsr.v2i1.2573 J. Sci. Res. 2 (1), 67-76 (2010)

\section{Introduction}

Glucose is a main source of energy for the cells that make up our muscles and other tissues. Blood sugar tests measure how well our body processes sugar (glucose). A normal fasting blood sugar result is lower than 100 milligrams of glucose per deciliter of blood (mg/dL) [1]. Hyperglycemia, or high blood glucose levels, is the hallmark of diabetic and it is linked to the development of long-term diabetic complications. Healthy people without diabetic typically have blood glucose levels of $65-110 \mathrm{mg} / \mathrm{dl}$ and $120-140 \mathrm{mg} / \mathrm{dl}$ one to two hours after eating [2,3]. Although infectious diseases still constitute the leading cause of mortality and morbidity in developing countries, WHO predicts that non-communicable

${ }^{1}$ Corresponding author: bnoor_ru08@yahoo.com 
diseases such as diabetes, cardiovascular disease, cancer, and chronic respiratory diseases will become the world's main disablers and killers within the next quarter-century [4].

Type-I diabetes is an autoimmune disease. An autoimmune disease results when the body's system for fighting infection (the immune system) turns against a part of the body. In diabetes, the immune system attacks and destroys the insulin-producing beta cells in the pancreas. The pancreas then produces little or no insulin. A person who has type-I diabetes must take insulin daily to live [5]. In type-II diabetic, the pancreas is usually producing enough insulin, but for unknown reasons the body cannot use the insulin effectively, a condition called insulin resistance. After several years, insulin production decreases. The result is the same as for type-I diabetes - glucose builds up in the blood and the body cannot make efficient use of its main source of fuel. The symptoms of type-II diabetes develop gradually [5]. The most common form of diabetic is type-II diabetic and this type of diabetic is most often associated with older age, obesity, physical inactivity, and ethnicities [6]. Investigating the prevalence of type-II Diabetic Mellitus (DM), impaired glucose tolerance and the factors affecting blood sugar level, it has been found that the sex, hyperlipoidemia, hypertriglyceredemia and hypertension as independent factors for the abnormalities in glucose tolerance; whereas, BMI and per day insulin and tablet intake affect blood sugar level for the both sexes and for both tablet or insulin users [7]. It has also been revealed that aging, overweight and a sedentary lifestyle are the important determinants in the prevalence of the diabetic during this transition period in Vietnam [8]. For non-insulin-dependent diabetic mellitus (NIDDM), impaired glucose tolerance (IGT) and hyper tension in rural community of Bangladesh, increased age has been considered as an important risk factor for all disorder related to diabetic whereas BMI associated risk have been significant with NIDDM and hypertension [9,10].

The main aim of this paper is to investigate the direct, indirect and joint contributions of the selected factors influencing blood sugar level of the diabetic patients of Rajshahi district in Bangladesh using path analysis.

\section{Data Source}

Out of 84 diagnostic and pathologies [11], there are only two well recognized diabetic diagnostic centers named "Rajshahi Diabetic Association and Diagnostic Center" at Laxmipur and "Diabetic Welfare Center, Talaimary, Rajshahi” in Rajshahi city. Theses two diabetic centers have been considered as our study areas. There were 5345 registered diabetic patients at both the diabetic diagnostic centers; out of them 3772 registered patients were in Rajshahi Diabetic Association and Diagnostic Center and 1573 in Diabetic Welfare Center. We serially numbered all those registered diabetic patients from the two centers' respective registered book and thereafter we selected 1069 diabetic patients through the process of linear systematic sampling procedure using the formula $N=n k$, where $N=5348, n=1069$ and $k=5$ [12]. Among 1069 patients there were 504 males and 565 females of whom 454 were tablet users and 615 insulin users. 


\section{Analytical Methodology}

The techniques employed in this study to examine the effects of various direct, indirect and concerned factors on blood sugar level of the patients who were taking tablet or insulin to control their blood sugar level using multivariate analysis named path analysis. $X_{i}$ (for tablet users) or $Y_{i}$ (for insulin users) be the $i$ th variable $(i=1,2,3, \ldots 11)$ and the dependent variable $\left(X_{11}\right.$ or $\left.Y_{11}\right)$ is blood sugar level of the diabetic patients. The following Table 1 represents the variables and their measurement used in the path analysis.

Table 1. Variables and their measurement used in the path analysis.

\begin{tabular}{|c|c|}
\hline Variables & Measurement \\
\hline$X_{1}$ or $Y_{1}=$ Total Number of Children & Total number of children of the diabetic patients. \\
\hline$X_{2}$ or $Y_{2}=$ Duration of Suffering & Suffering period of the diabetic patients (in year). \\
\hline$X_{3}$ or $Y_{3}=$ Systolic Pressure & $\begin{array}{l}\text { The blood pressure at the time of inhalation of oxygen by the } \\
\text { lung. }\end{array}$ \\
\hline$X_{4}$ or $Y_{4}=$ Duration of Education & Duration of education in schooling year. \\
\hline$X_{5}$ or $Y_{5}=$ Diastolic Pressure & $\begin{array}{l}\text { The blood pressure at the time of exhalation of oxygen to the } \\
\text { blood vessels by the lung. }\end{array}$ \\
\hline$X_{6}$ or $Y_{6}=$ Age & The age of the diabetic patients. \\
\hline$X_{7}$ or $Y_{7}=$ Calorie Intake & Calorie intake by the diabetic patients \\
\hline$X_{8}$ or $Y_{8}=\mathrm{BMI}$ & Body Mass Index (in kg/ $\mathrm{cm}^{2}$ ). \\
\hline$X_{9}$ or $Y_{9}=$ Walking distance (Km/Min.) & Daily walking distance covered by the patients (in km/min). \\
\hline$X_{10}$ or $Y_{10}=$ Tablet or Insulin Intake. & Daily tablet or insulin intake by the patients (in mg and cc). \\
\hline$X_{11}=$ Blood Sugar Level & $\begin{array}{l}\text { Blood sugar level measured after two hours of breakfast (ABF) of } \\
\text { the patients (in mg/dl). }\end{array}$ \\
\hline
\end{tabular}

According to the causal ordering of variables, the selected set of variables may be divided into three groups that are given in Table 2:

Table 2. Category of the different variables.

\begin{tabular}{lc}
\hline Exogenous Variable & $\left\{X_{,}, X_{2}, X_{3}, X_{4}\right.$ and $\left.X_{5}\right\}$ or $\left\{Y_{1}, Y_{2}, Y_{3}, Y_{4}\right.$ and $\left.Y_{5}\right\}$ \\
Endogenous Variable & $\left\{X_{6,}, X_{7}, X_{8}, X_{9}\right.$ and $\left.X_{10}\right\}$ or $\left\{Y_{6,}, Y_{7}, Y_{8}, Y_{9}\right.$ and $\left.Y_{10}\right\}$ \\
Dependent Variable & $\left\{X_{11}\right\}$ or $\left\{Y_{11}\right\}$ \\
\hline
\end{tabular}

Note: $X_{\mathrm{i}}$ for tablet users and $Y_{\mathrm{i}}$ for insulin users.

In this study one of the main tasks in path diagram (Figs. 1 and 2) represent the hypothetical causal model relationship between blood sugar level and some of its determinants of the tablet and insulin user diabetic patients.

This model is recursive path model in which each variable assumed to be dependent upon all prior causal variables [13]. The system of equation for model can be written as:

$$
X_{6}=p_{61} X_{1}+p_{62} X_{2}+p_{63} X_{3}+p_{64} X_{4}+p_{65} X_{5}+e_{6 x}
$$

or

$$
\begin{aligned}
& Y_{6}=q_{61} Y_{1}+q_{62} Y_{2}+q_{63} Y_{3}+q_{64} Y_{4}+q_{65} Y_{5}+e_{6 y} \\
& X_{7}=p_{71} X_{1}+p_{72} X_{2}+p_{73} X_{3}+p_{74} X_{4}+p_{75} X_{5}+p_{76} X_{6}+e_{7 x}
\end{aligned}
$$

or

$$
\begin{aligned}
& Y_{7}=q_{71} Y_{1}+q_{72} Y_{2}+q_{73} Y_{3}+q_{74} Y_{4}+q_{75} Y_{5}+q_{76} Y_{6}+e_{7 y} \\
& X_{8}=p_{81} X_{1}+p_{82} X_{2}+p_{83} X_{3}+p_{84} X_{4}+p_{85} X_{5}+p_{86} X_{6}+p_{87} X_{7}+e_{8 x}
\end{aligned}
$$


or

$$
\begin{aligned}
& Y_{8}=q_{81} Y_{1}+q_{82} Y_{2}+q_{83} Y_{3}+q_{84} Y_{4}+q_{85} Y_{5}+q_{86} Y_{6}+q_{87} Y_{7}+e_{8 y} \\
& X_{9}=p_{91} X_{1}+p_{92} X_{2}+p_{93} X_{3}+p_{94} X_{4}+p_{95} X_{5}+p_{96} X_{6}+p_{97} X_{7}+p_{98} X_{8}+e_{9 x}
\end{aligned}
$$

or

$$
\begin{aligned}
& Y_{9}=q_{91} Y_{1}+q_{92} Y_{2}+q_{93} Y_{3}+q_{94} Y_{4}+q_{95} Y_{5}+q_{96} Y_{6}+q_{97} Y_{7}+q_{98} Y_{8}+e_{9 y} \\
& X_{10}=p_{101} X_{1}+p_{102} X_{2}+p_{103} X_{3}+p_{104} X_{4}+p_{105} X_{5}+p_{106} X_{6}+p_{107} X_{7}+p_{108} X_{8}+p_{109} X_{9}+e_{10 x}
\end{aligned}
$$

or

$$
\begin{aligned}
& Y_{10}=q_{101} Y_{1}+q_{102} Y_{2}+q_{103} Y_{3}+q_{104} Y_{4}+q_{105} Y_{5}+q_{106} Y_{6}+q_{107} Y_{7}+q_{108} Y_{8}+q_{109} Y_{9}+e_{10 y} \\
& X_{11}=p_{111} X_{1}+p_{112} X_{2}+p_{113} X_{3}+p_{114} X_{4}+p_{115} X_{5}+p_{116} X_{6}+p_{117} X_{7}+p_{118} X_{8}+p_{119} X_{9}+p_{1110} X_{10}+e_{11 x}
\end{aligned}
$$

or

$$
Y_{11}=q_{111} Y_{1}+q_{112} Y_{2}+q_{113} Y_{3}+q_{114} Y_{4}+q_{115} Y_{5}+q_{116} Y_{6}+q_{117} Y_{7}+q_{118} Y_{8}+q_{119} Y_{9}+q_{1110} Y_{10}+e_{11 y}
$$

(Note : $X$ for tablet users and $Y$ for insuline users)

where, $p_{i j}$ (or $q_{i j}$ ) are the path coefficients and $e_{i x}\left(e_{i y}\right)$ are the random disturbance terms. All the random disturbance terms are mutually independent and the independent of their corresponding explanatory variables. The residual of the path coefficients can also be estimated with case from the regression equation as square root of $\left(1-R^{2}\right)$, where, $R^{2}$ (unadjusted) is the multiple correlation coefficients (square) of the regression equations. From the path analysis the direct effects, joint effects, implied effects and total effects of each selected explanatory variables on blood sugar level are obtained separatyely for the patients who are used to take tablet for controlling their blood sugar and for the patients who are used to take insulin for controlling their blood sugar level.

\section{Results and Discussion}

Tables 3 and 4 present the zero order correlation coefficients among the selected variablers. For the tablet users, Tables 5 and 6 respectively represent the total absolute effect and percentage of the total absolute effect on blood sugar through endogenous variables. Similarly, For the insulin users, the total absolute effect and their corresponding percentage through endogenous variables are prsented in Tables 7 and 8, respectively.

Table 3. Zero order correlation coefficients among the selected variables for the diabetic patients taking tablet.

\begin{tabular}{cccccccccccc}
\hline & $X_{1}$ & $X_{2}$ & $X_{3}$ & $X_{4}$ & $X_{5}$ & $X_{6}$ & $X_{7}$ & $X_{8}$ & $X_{9}$ & $X_{10}$ & $X_{11}$ \\
\hline$X_{1}$ & 1 & $0.082^{* *}$ & 0.028 & $-0.314^{* *}$ & 0.039 & $0.502^{* *}$ & $0.070^{*}$ & -0.022 & -0.012 & 0.033 & 0.033 \\
$X_{2}$ & 1 & 0.034 & 0.024 & 0.056 & $0.187^{* *}$ & -0.059 & 0.027 & -0.044 & 0.057 & 0.008 \\
$X_{3}$ & & 1 & 0.015 & $0.154^{* *}$ & 0.037 & 0.036 & 0.021 & 0.050 & -0.018 & $0.219^{* *}$ \\
$X_{4}$ & & & 1 & 0.002 & $-0.072^{*}$ & 0.012 & 0.047 & $0.076^{*}$ & -0.006 & -0.001 \\
$X_{5}$ & & & & 1 & 0.013 & 0.019 & 0.024 & 0.020 & -0.030 & $0.303^{* *}$ \\
$X_{6}$ & & & & & 1 & 0.033 & -0.025 & -0.056 & 0.016 & 0.005 \\
$X_{7}$ & & & & & & 1 & $0.108^{* *}$ & -0.019 & -0.059 & $0.093^{* *}$ \\
$X_{8}$ & & & & & & & 1 & -0.027 & 0.005 & $0.019^{* *}$ \\
$X_{9}$ & & & & & & & & 1 & -0.002 & -0.041 \\
$X_{10}$ & & & & & & & & & & 1 & 0.061 \\
$X_{11}$ & & & & & & & & & & & \\
\hline
\end{tabular}


From Tables 3 and 4, it is evident that systolic pressure $\left(X_{3}\right.$ or $\left.Y_{3}\right)$, diastolic pressure $\left(X_{5}\right.$ or $\left.Y_{5}\right)$, calorie intake $\left(X_{7}\right.$ or $\left.Y_{7}\right)$, have significant positive relationships with blood sugar level $\left(X_{11}\right.$ or $\left.Y_{11}\right)$. We also observe that the positive significant relationships have total number of children $\left(X_{1}\right.$ or $\left.Y_{1}\right)$ with duration of suffering from diabetic $\left(X_{2}\right.$ or $\left.Y_{2}\right)$, age $\left(X_{6}\right.$ or $\left.Y_{6}\right)$; duration of suffering $\left(X_{2}\right.$ or $\left.Y_{2}\right)$ with age $\left(X_{6}\right.$ or $\left.Y_{6}\right)$; systolic pressure $\left(X_{3}\right.$ or $\left.Y_{3}\right)$ with

Table 4. Zero order correlation coefficients among the selected variables for the diabetic patients taking insulin.

\begin{tabular}{|c|c|c|c|c|c|c|c|c|c|c|c|}
\hline & $Y_{1}$ & $Y_{2}$ & $Y_{3}$ & $Y_{4}$ & $Y_{5}$ & $Y_{6}$ & $Y_{7}$ & $Y_{8}$ & $Y_{9}$ & $Y_{10}$ & $Y_{11}$ \\
\hline$Y_{1}$ & 1 & $0.082 * *$ & 0.028 & $-0.314^{* *}$ & 0.023 & $0.502 * *$ & 0.070 * & -0.022 & -0.012 & 0.022 & 0.033 \\
\hline$Y_{2}$ & & 1 & 0.034 & 0.024 & 0.056 & $0.187^{* *}$ & .059 & 0.027 & -.044 & 0.008 & 0.038 \\
\hline$Y_{3}$ & & & 1 & -0.015 & $0.154^{* *}$ & -0.037 & 0.036 & 0.021 & -0.050 & 0.054 & $0.219 * *$ \\
\hline$Y_{4}$ & & & & 1 & 0.002 & $-0.072 *$ & 0.012 & 0.047 & $0.076^{*}$ & -0.014 & -0.001 \\
\hline$Y_{5}$ & & & & & 1 & 0.013 & 0.019 & 0.024 & -0.020 & 0.059 & $0.303^{* *}$ \\
\hline$Y_{6}$ & & & & & & 1 & 0.033 & -0.025 & -0.056 & 0.022 & 0.005 \\
\hline$Y_{7}$ & & & & & & & 1 & $0.108 * *$ & -0.019 & 0.030 & $0.093^{* *}$ \\
\hline$Y_{8}$ & & & & & & & & 1 & -0.027 & 0.033 & 0.19 \\
\hline$Y_{9}$ & & & & & & & & & 1 & $-0.086^{* *}$ & -0.041 \\
\hline$Y_{10}$ & & & & & & & & & & 1 & $0.219 * *$ \\
\hline$Y_{11}$ & & & & & & & & & & & 1 \\
\hline
\end{tabular}

diastolic pressure $\left(X_{5}\right.$ or $\left.Y_{5}\right)$; duration of education $\left(X_{4}\right.$ or $\left.Y_{4}\right)$ with walking distance $\left(X_{9}\right.$ or $\left.Y_{9}\right)$ and calorie intake $\left(X_{7}\right.$ or $\left.Y_{7}\right)$. The results indicate that blood sugar level $\left(X_{11}\right.$ or $\left.Y_{11}\right)$ is highly influenced by age $\left(X_{6}\right.$ or $\left.Y_{6}\right)$, systolic pressure $\left(X_{3}\right.$ or $\left.Y_{3}\right)$, diastolic pressure $\left(X_{5}\right.$ or $\left.Y_{5}\right)$ and calorie intake $\left(X_{7}\right.$ or $\left.Y_{7}\right)$, which in turn influence BMI $\left(X_{8}\right.$ or $\left.Y_{8}\right)$, and it was found that diabetic is associated with age, BMI, blood pressure, triglyceride, HDL, education level, exercise, and a family history of diabetic [14]. But the variables, total number of children $\left(X_{1}\right.$ or $\left.Y_{1}\right)$ with duration of education $\left(X_{4}\right.$ or $\left.Y_{4}\right)$ and duration of education $\left(X_{4}\right.$ or $Y_{4}$ ) with age $\left(X_{6}\right.$ or $\left.Y_{6}\right)$ have significant negative relationships exist between them.

We have tried to obtain the direct, indirect and implied effects and various path coefficients of each of the explanatory variables from path analysis. In case of insulin users diabetic patients, out of 36, 15 hypothesized paths are statistically significant, again, out of 5, 3 endogenous variables named calorie intake $\left(Y_{7}\right)$, walking distance $\left(Y_{9}\right)$ and per day insulin intake $\left(Y_{10}\right)$ have significant direct effect on blood sugar level $\left(X_{11}\right)$ (Fig. 2). This result is supported by other workers as they found that calorie intake, walking distance and per day insulin intake as significant risk factors of diabetic [15]. In case tablet users' diabetic patients, out of 36, 14 hypothesized paths are statistically significant. Whereas, out of 5, 4 endogenous variables as age $\left(X_{6}\right)$, calorie intake $\left(X_{7}\right)$, BMI $\left(X_{8}\right)$ and walking distance $\left(X_{9}\right)$ have significant direct effect on blood sugar level $\left(X_{11}\right)$ (Fig. 1). From Fig. 1, it shows that the indirect significant effects on blood sugar level $\left(\mathrm{X}_{11}\right)$ are total number of children $\left(X_{1}\right)$ through calorie intake $\left(X_{7}\right)$; duration of suffering from diabetic $\left(X_{2}\right)$ through age $\left(X_{6}\right)$ as well as calorie intake $\left(X_{7}\right)$; systolic pressure $\left(X_{3}\right)$ through age $\left(X_{6}\right)$; duration of education $\left(X_{4}\right)$ through age $\left(X_{6}\right)$, BMI $\left(X_{8}\right)$ as well as walking distance $\left(X_{9}\right)$. From Fig. 2, the indirect significant effects on blood sugar level $\left(Y_{11}\right)$ are total number of children $\left(Y_{1}\right)$ through age $\left(Y_{6}\right)$, calorie intake $\left(Y_{7}\right)$ and BMI $\left(Y_{8}\right)$; exogenous variable duration of suffering from diabetic $\left(Y_{2}\right)$ through age $\left(Y_{6}\right)$ and calories intake $\left(Y_{7}\right)$; systolic pressure $\left(Y_{3}\right)$ through age $\left(Y_{6}\right)$; duration of education $\left(Y_{4}\right)$ through age $\left(Y_{6}\right)$, BMI $\left(Y_{8}\right)$ and walking habit $\left(Y_{9}\right)$; and diastolic pressure $\left(Y_{5}\right)$ through insulin intake $\left(Y_{10}\right)$. 


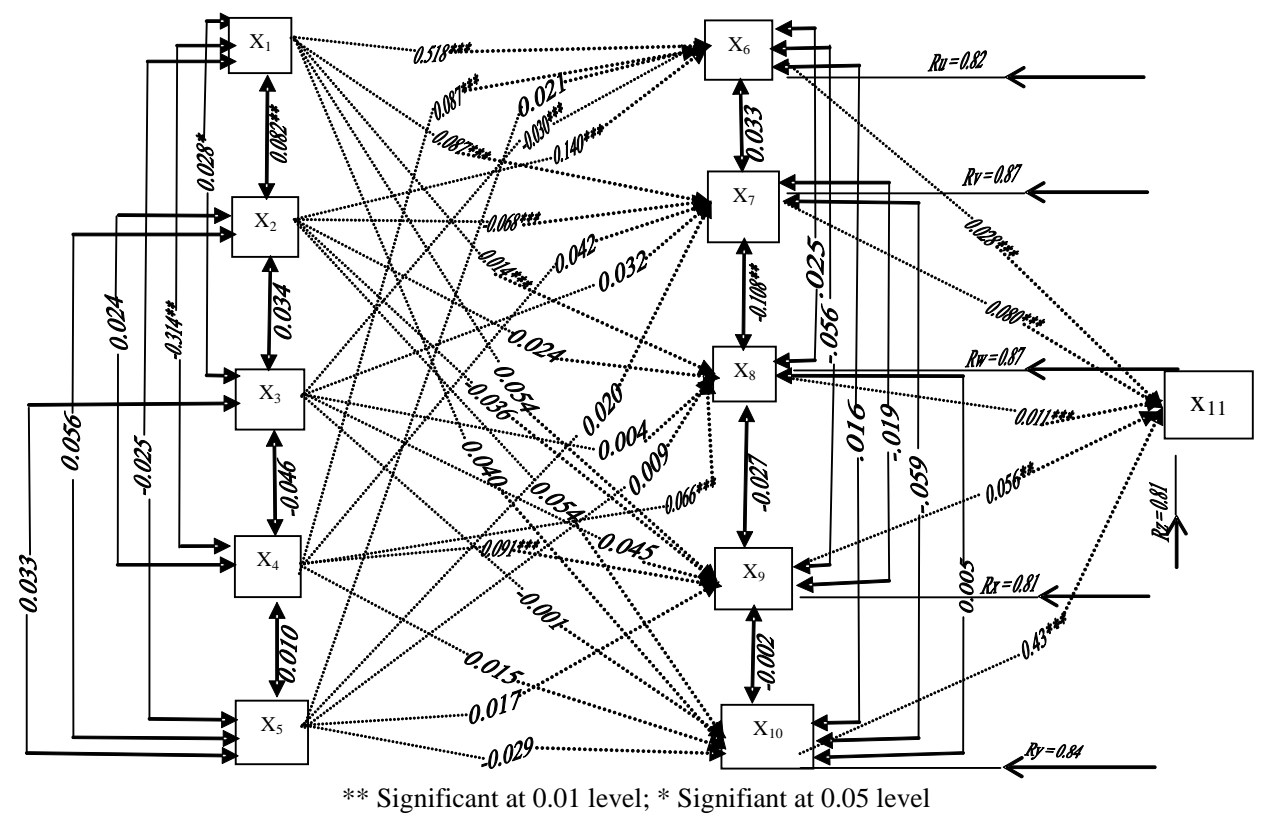

Fig. 1. Path diagram for the selected factors affecting blood sugar level through endogenouse variables (For tablet users).

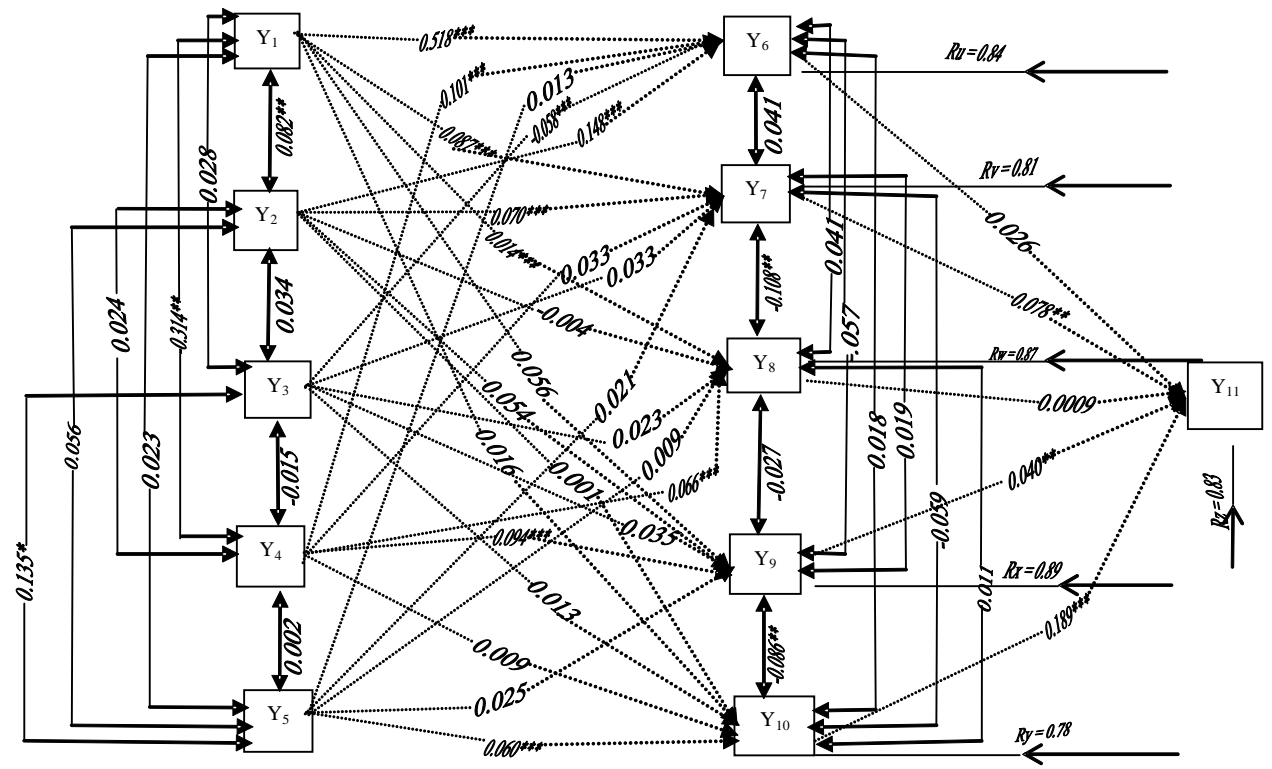

** Significant at 0.01 level; * Signifiant at 0.05 level

Fig. 2. Path diagram for the selected factors affecting the blood sugar level through endogenouse variables (For insuli users). 
We observe that in case of tablet users, total effect of the total number of children $\left(X_{1}\right)$ on blood sugar level $\left(X_{11}\right)$ is 0.667 (Table 5 ) in the same direction of which about $68.24 \%$ are transmitted through age $\left(X_{6}\right)$ in same direction and about $6.06 \%$ are transmitted through its implied effect in opposite direction then about $11.46 \%, 1.84 \%, 7.11 \%$ and $5.27 \%$ in same direction acts through calorie intake $\left(X_{7}\right)$, BMI $\left(X_{8}\right)$, walking habit of the patients $\left(X_{9}\right)$ and tablet intake $\left(X_{10}\right)$ respectively (Table 6). Total effect of duration of suffering from diabetic $\left(X_{2}\right)$ on blood sugar level $\left(X_{11}\right)$ is 0.128 in the same direction (Table 5) of which about $41.66 \%, 7.14 \%$ and $5.27 \%$ are transmitted through age of respondents $\left(X_{6}\right)$, BMI of the respondents $\left(X_{8}\right)$, and per day tablet intake $\left(X_{10}\right)$ in the same direction and about $4.16 \%$ is transmitted through it's implied effect in the same direction (Table 6).

Then, $20.23 \%$ and $16.07 \%$ are transmitted in opposite direction through calorie intake $\left(X_{7}\right)$, and tablet intake $\left(X_{10}\right)$ respectively (Table 6). Total effect of systolic pressure $\left(X_{3}\right)$ on blood sugar level $\left(X_{11}\right)$ is 0.278 (Table 5 ) in the same direction of which about $3.35 \%$ is transmitted through tablet intake $\left(X_{10}\right)$ in opposite direction and about $59.39 \%$ is transmitted through it's implied effect in same direction then $10.06 \%, 10.73 \%, 1.34 \%$ and $15.10 \%$ are transmitted in same direction through age $\left(X_{6}\right)$, calorie intake $\left(X_{7}\right)$, BMI $\left(X_{8}\right)$, walking habit $\left(X_{9}\right)$, respectively (Table 6). Total effect of educational qualification of the respondents $\left(X_{4}\right)$ on blood sugar level is 0.278 (Table 5) in the same direction and of which $29.79 \%, 14.38 \%, 17.12 \%, 31.36 \%$ and $5.13 \%$ have been transmitted through age of the respondents $\left(X_{6}\right)$, calorie intake $\left(X_{7}\right)$, BMI $\left(X_{8}\right)$, walking habit $\left(X_{9}\right)$ and through tablet intake $\left(X_{10}\right)$ respectively in the same direction and only $2.39 \%$ has been transmitted through its implied effect in opposite direction (Table 6).

Table 5. Results for the selected factors of blood sugar level through endogenous variables (For tablet users).

\begin{tabular}{ccccccccccccc}
\hline $\begin{array}{c}\text { Dependent } \\
\text { variable }\end{array}$ & $\begin{array}{c}\text { Exo. } \\
\text { variable }\end{array}$ & $\begin{array}{c}\text { Total } \\
\text { association }\end{array}$ & $\begin{array}{c}\text { Non- } \\
\text { casual } \\
\text { effect }\end{array}$ & $\begin{array}{c}\text { Total } \\
\text { effect }\end{array}$ & $X_{6}$ & $X_{7}$ & $X_{8}$ & $X_{9}$ & $X_{10}$ & $\begin{array}{c}\text { Other } \\
\text { variables } \\
\text { (implied } \\
\text { effect) }\end{array}$ & $\begin{array}{c}\text { Direct } \\
\text { effect }\end{array}$ \\
\hline & $X_{1}$ & 0.033 & 0.634 & 0.667 & 0.518 & 0.087 & 0.014 & 0.054 & 0.040 & -0.046 \\
& $X_{2}$ & 0.008 & 0.12 & 0.128 & 0.140 & -0.068 & 0.024 & -0.036 & 0.054 & 0.014 \\
& $X_{3}$ & $0.219^{* *}$ & 0.059 & 0.278 & 0.030 & 0.032 & 0.004 & 0.045 & -0.010 & 0.177 \\
$X_{11}$ & $X_{4}$ & -0.001 & 0.279 & 0.278 & 0.087 & 0.042 & 0.050 & 0.091 & 0.015 & -0.007 & \\
& $X_{5}$ & $0.303^{* *}$ & 0.019 & 0.322 & 0.021 & 0.020 & 0.020 & 0.017 & -0.029 & 0.273 & \\
& $X_{6}$ & 0.005 & -0.002 & -0.007 & & 0.006 & -0.020 & -0.069 & -0.012 & & 0.028 \\
& $X_{7}$ & $0.093^{* *}$ & 0.047 & 0.14 & & & 0.108 & 0.009 & -0.057 & & 0.080 \\
& $X_{8}$ & 0.019 & -0.004 & -0.021 & & & & -0.030 & -0.002 & & 0.011 \\
& $X_{9}$ & -0.041 & 0.103 & 0.062 & & & & & 0.006 & & 0.056 \\
& $X_{10}$ & 0.061 & -0.018 & 0.043 & & & & & & & 0.043 \\
\hline
\end{tabular}

Note: Non-casual effect $=$ Total effect - Total association and Exo. $=$ Exogenous

** Significant at 0.01 level; * Significant at 0.05 level 
Table 6. Percentage of the total absolute effect on the blood sugar level through endogenous variables (For tablet users).

\begin{tabular}{|c|c|c|c|c|c|c|c|c|}
\hline \multirow{2}{*}{$\begin{array}{l}\text { Dependent } \\
\text { variable }\end{array}$} & \multirow{2}{*}{$\begin{array}{l}\text { Exogenous } \\
\text { variable }\end{array}$} & \multicolumn{5}{|c|}{ Percentage of indirect effect through } & \multirow{2}{*}{$\begin{array}{l}\text { Other variables } \\
\text { (implied effect) }\end{array}$} & \multirow{2}{*}{$\begin{array}{l}\text { Direct } \\
\text { effect }\end{array}$} \\
\hline & & $X_{6}$ & $X_{7}$ & $X_{8}$ & $X_{9}$ & $X_{10}$ & & \\
\hline \multirow{10}{*}{$X_{11}$} & $X_{1}$ & 68.24 & 11.46 & 1.84 & 7.11 & 5.27 & 6.06 & \\
\hline & $X_{2}$ & 41.66 & 20.23 & 7.14 & 10.71 & 16.07 & 4.16 & \\
\hline & $X_{3}$ & 10.06 & 10.73 & 1.34 & 15.10 & 3.35 & 59.39 & \\
\hline & $X_{4}$ & 29.79 & 14.38 & 17.12 & 31.16 & 5.13 & 2.39 & \\
\hline & $X_{5}$ & 5.52 & 5.26 & 5.26 & 4.47 & 7.63 & 71.87 & \\
\hline & $X_{6}$ & & 4.44 & 14.81 & 51.11 & 8.88 & & 20.74 \\
\hline & $X_{7}$ & & & 42.51 & 3.54 & 22.44 & & 31.49 \\
\hline & $X_{8}$ & & & & 69.76 & 4.65 & & 25.58 \\
\hline & $X_{9}$ & & & & & 9.67 & & 90.32 \\
\hline & $X_{10}$ & & & & & & & 100 \\
\hline
\end{tabular}

The exogenous variable diastolic pressure $\left(X_{5}\right)$ have the total effect 0.322 (Table 5) on blood glucose level $\left(X_{11}\right)$ in the same direction of which only 5.52\%, 5.26\%, 5.26\% and $4.47 \%$ are transmitted through age of the respondents, $\left(X_{6}\right)$, calorie intake $\left(X_{7}\right)$, BMI $\left(X_{8}\right)$ and walking habit $\left(X_{9}\right)$ in the same direction and a large percentage of $71.63 \%$ is transmitted through its implied effect in the same direction respectively, then $7.64 \%$ is transmitted through per day insulin intake $\left(X_{10}\right)$ by the patients in the opposite direction. (Table 6).

Among the patients who are used to and are prescribed to take insulin for controlling their blood sugar level, it is observed from Table 7 that total effect of total number of children $\left(Y_{1}\right)$ on blood glucose level $\left(Y_{11}\right)$ is 0.739 (Table 7) in same direction of which $70.09 \%, 9.65 \%, 9.13 \%, 7.20 \%, 1.93 \%$, have been transmitted in same direction through age of the respondents $\left(Y_{6}\right)$, calorie intake $\left(Y_{7}\right)$, BMI of the respondents $\left(Y_{8}\right)$, walking habit of the respondents $\left(Y_{9}\right)$ and amount of per day insulin intake $\left(Y_{10}\right)$ in the same direction respectively. A few percent (3.6\%) has been transmitted through its implied effects in the same direction (Table 8). The total effect of duration of suffering from diabetic $\left(\mathrm{Y}_{2}\right)$ to blood sugar level $\left(Y_{11}\right)$ is 0.078 (Table 7 ) in the same direction while, of $0.078,48.95 \%$, $8.39 \%$ and only $0.69 \%$ have been transmitted in same direction through age of the respondents $\left(Y_{6}\right)$, BMI of the respondents $\left(Y_{8}\right)$ and walking distance $\left(Y_{9}\right)$ respectively, and $5.59 \%$ has been transmitted through its implied effect in the same direction, and $23.77 \%$ and $12.58 \%$ have been transmitted in opposite direction through calorie intake $\left(Y_{7}\right)$, per day insulin intake $\left(Y_{10}\right)$ respectively (Table 8$)$.

The total effect of the systolic pressure $\left(Y_{3}\right)$ on the blood glucose level is 0.328 (Table 7 ) in same direction. Of the total effect of $0.328,9.14 \%, 9.75 \%, 1.21 \%, 13.71 \%$ and $15.24 \%$ are transmitted in the opposite direction through age $\left(Y_{6}\right)$, calorie intake $\left(Y_{7}\right)$, BMI $\left(Y_{8}\right)$, walking distance $\left(Y_{9}\right)$ and insulin intake $\left(Y_{10}\right)$ respectively in the same direction, and $50.91 \%$ is transmitted through its implied effect towards same direction (Table 8). 
Table 7. Results for the selected factors of blood sugar level through endogenous variables (For insulin users).

\begin{tabular}{ccccccccccccc}
\hline $\begin{array}{c}\text { Dependent } \\
\text { variable }\end{array}$ & $\begin{array}{c}\text { Exo. } \\
\text { variable }\end{array}$ & $\begin{array}{c}\text { Total } \\
\text { association }\end{array}$ & $\begin{array}{c}\text { Non- } \\
\text { casual } \\
\text { effect }\end{array}$ & $\begin{array}{c}\text { Total } \\
\text { effect }\end{array}$ & $Y_{6}$ & $Y_{7}$ & $Y_{8}$ & $Y_{9}$ & $Y_{10}$ & $\begin{array}{c}\text { Other } \\
\text { variables } \\
\text { (implied } \\
\text { effect) }\end{array}$ & $\begin{array}{c}\text { Direct } \\
\text { effect }\end{array}$ \\
\hline & $Y_{1}$ & 0.033 & 0.706 & 0.739 & 0.518 & 0.087 & 0.014 & 0.054 & 0.016 & 0.050 \\
& $Y_{2}$ & 0.038 & 0.04 & 0.078 & 0.140 & -0.068 & 0.024 & -0.036 & 0.002 & 0.016 \\
& $Y_{3}$ & $0.219 * *$ & 0.109 & 0.328 & 0.030 & 0.032 & 0.004 & 0.045 & 0.050 & 0.167 \\
$Y_{11}$ & $Y_{4}$ & -0.001 & 0.296 & 0.286 & 0.087 & 0.042 & 0.050 & 0.091 & 0.023 & -0.007 & \\
& $Y_{5}$ & $0.333^{* *}$ & 0.092 & 0.395 & 0.021 & 0.020 & 0.020 & 0.017 & 0.052 & 0.265 & 0.026 \\
& $Y_{6}$ & 0.005 & -0.052 & -0.057 & & 0.006 & -0.029 & -0.069 & 0.009 & & 0.078 \\
& $Y_{7}$ & $0.093^{* *}$ & 0.129 & 0.222 & & & 0.108 & 0.009 & 0.027 & & 0.009 \\
& $Y_{80}$ & 0.19 & 0.181 & -0.009 & & & & -0.030 & 0.012 & & 0.040 \\
& $Y_{9}$ & -0.041 & 0.036 & -0.005 & & & & & -0.090 & & 0.189 \\
\hline
\end{tabular}

Note: Non-casual effect $=$ Total effect - Total association and Exo. $=$ Exogenous;

** Significant at 0.01 level; * Significant at 0.05 level.

Table 8. Percentage of the total absolute effect on the blood sugar level through endogenous variables for insulin users (For insulin users).

\begin{tabular}{|c|c|c|c|c|c|c|c|c|}
\hline \multirow{2}{*}{$\begin{array}{l}\text { Dependent } \\
\text { variable }\end{array}$} & \multirow{2}{*}{$\begin{array}{l}\text { Exogenous } \\
\text { variable }\end{array}$} & \multicolumn{5}{|c|}{ Percentage of indirect effect through } & \multirow{2}{*}{$\begin{array}{l}\text { Other variables } \\
\text { (implied effect) }\end{array}$} & \multirow{2}{*}{$\begin{array}{l}\text { Direct } \\
\text { effect }\end{array}$} \\
\hline & & $Y_{6}$ & $Y_{7}$ & $Y_{8}$ & $Y_{9}$ & $Y_{10}$ & & \\
\hline \multirow{10}{*}{$Y_{11}$} & $Y_{1}$ & 70.09 & 9.65 & 9.13 & 7.20 & 1.93 & 3.60 & \\
\hline & $Y_{2}$ & 48.95 & 23.77 & 8.39 & 12.58 & 0.69 & 5.59 & \\
\hline & $Y_{3}$ & 9.14 & 9.75 & 1.21 & 13.71 & 15.24 & 50.91 & \\
\hline & $Y_{4}$ & 29.00 & 14.00 & 16.66 & 30.33 & 7.66 & 2.33 & \\
\hline & $Y_{5}$ & 5.31 & 5.06 & 5.06 & 4.30 & 13.16 & 67.08 & \\
\hline & $Y_{6}$ & & 4.31 & 20.86 & 49.64 & 6.47 & & 18.70 \\
\hline & $Y_{7}$ & & & 48.64 & 4.05 & 12.16 & & 35.13 \\
\hline & $Y_{8}$ & & & & 58.82 & 23.52 & & 17.64 \\
\hline & $Y_{9}$ & & & & & 69.23 & & 30.76 \\
\hline & $Y_{10}$ & & & & & & & 100 \\
\hline
\end{tabular}

The total effect of educational qualification $\left(Y_{4}\right)$ on blood sugar level $\left(Y_{11}\right)$ is 0.286 (Table 7) of which 29\%, 14\%, 16.66\%, 30.33\% and 7.66\% have been transmitted in same direction through age of the respondents $\left(Y_{6}\right)$, calorie intake, BMI of the respondents $\left(Y_{8}\right)$, walking distance $\left(Y_{9}\right)$ and per day insulin intake $\left(Y_{10}\right)$ respectively, only $2.33 \%$ is transmitted through its implied effect in the opposite direction (Table 8). The total effect of diastolic pressure $\left(Y_{5}\right)$ on blood sugar level $\left(Y_{11}\right)$ is 0.395 (Table 7) of which only $5.31 \%, 5.06 \%, 4.30 \%$ and $13.16 \%$ have been transmitted through age of the respondents $\left(Y_{6}\right)$, calorie intake $\left(Y_{7}\right)$, BMI of the respondents $\left(Y_{8}\right)$ and daily insulin intake $\left(Y_{10}\right)$ in same direction and at the same time $67.08 \% \%$ has been transmitted through its implied effect towards the same direction (Table 8). 


\section{Conclusion}

From this study, it has been revealed that for the tablet users, systolic pressure, diastolic pressure, calorie intake and body mass index have direct positive and significant effect on blood glucose level. For the insulin users, systolic pressure, diastolic pressure, calorie intake and per day insulin intake have direct positive significant effect on blood sugar level. For both insulin and tablet users, systolic and diastolic pressures have a higher indirect effect on blood sugar level through their respective implied effect in the same direction. The finding shows that both systolic and diastolic blood pressure have a great hold on the diabetic patients' blood sugar level. Walking habit has a good contribution in the case of controlling blood glucose level for both types of the patient but for the tablet users this contribution is more effective in controlling the blood glucose level. Therefore, walking habit should be a noteworthy regulatory work for the diabetic patients. We may conclude that with the habit of taking more accurate and regulatory calorie intake, having the habit of walking and controlling blood pressure, in a word through giving up sedentary life style and maintaining a disciplined and regulatory life, a diabetic patient could maintain a safe and normal life.

\section{Reference}

1. C. Snehalatha, A. Kapur, and V. Vijay, J. Assoc. Physicians India 51, 766 (2001).

2. H. G. Allen, J. C. Allen, L. C. Boyd, and B. P. Alston-Mills Can, Nutrition 19, 584 (2003). doi:10.1016/S0899-9007(03)00090-X

3. N. D. Kim, K. T. Mary, L. Karen, C. Gary, M. Neil, and Gsc. D. Francine, Obstet Gynecol. 194, 339 (2005).

4. World Health Organization, World Diabetic: A News Letter, 3 (2002).

5. Diabetes - A brief historical aspect; A Handbook of Diabetes Mellitus, New Mediwave Publication - LUPN 45 (2001).

6. A. M. Habori, A. M. Mamari and A. A. Meeri, Diabetic Res. Clin. Pract. 65, 275 (2004). doi:10.1016/j.diabres.2004.02.001

7. L. N. Duc Son, T. T. Hanh, K. Kusama, D. Kunni, T. Sakai, N. T. Hung, and S. Yamamoto, J. Am. Coll Nutr. 24, 229 (2008).

8. C. G. Sonomon, F. B. Hu, A. Dunaif, J. Rich-Edwards, W. C. Willett, D. J. Hunter, G. A. Colditz, F. E. Speizer, and J. E. Manson, JAMA 286, 2421 (2004). doi:10.1001/jama.286.19.2421

9. M. A. Sayeed, A. Banu, A. R. Khan, and M. Z. Hussain, Diabetic Care 18, 555 (1995). doi:10.2337/diacare.18.4.555

10. H. King, R. E. Aubert, and W. H. Herman, Diabetic Care 16, 157 (1998). doi:10.2337/diacare.16.1.157

11. Register book of Rajshahi Civil Surgeon Office (June 2008).

12. Daroga Singh, and F. S. Chaudhary, The Theory and Analysis of Sample Survey Designs, $3^{\text {rd }}$ Ediation (New Age Internatioal (P) Limited, New Delhi, 1997).

13. C. Chandrasekaran, H. Hermalin, D. R. Jornal of Royal Statistical Society, Series C, 21, 113 (1975).

14. S. M. Kim, J. S. Lee, J. Lee, J. K. Na, J. H. Han, D. K. Yoon, S. H. Baik, D. S. Choi, and K. M. Chi, Diabetic Care 29, 226 (2006). doi:10.2337/diacare.29.02.06.dc05-0481

15. M. A. Sayeed, M. Hajera, A. K. Parvin, A. A. Khandakar, B. Akhter, R. Bazlur, and A. K. Azad, Diabetic Care, 27, 1054 (2007). doi:10.2337/diacare.27.5.1054 